\title{
Growth Velocity and Factors Associated with Poor Postnatal Growth Rate Among Preterm Infants at KCMC: A Prospective Cohort Study
}

This article was published in the following Dove Press journal: Research and Reports in Neonatology

\author{
Isaac E Mlay iD ${ }^{\text {I,2 }}$ \\ Deborah N Mchaile (iD) ${ }^{1,2}$ \\ Aisa M Shayo ${ }^{1,2}$ \\ 'Department of Pediatrics and Child \\ Health, Kilimanjaro Christian Medical \\ University College, Kilimanjaro, Tanzania; \\ ${ }^{2}$ Department of Pediatrics and Child \\ Health, Kilimanjaro Christian Medical \\ Centre, Kilimanjaro, Tanzania
}

Background: Preterm poor growth during early infancy is a major problem that can lead into adverse growth and neurodevelopmental outcomes both in the early and later stages of life, contributing to the burden of malnutrition in under-fives globally, particularly in low resource settings. The aim of this study was to determine the growth velocity in preterm infants compared with international standards of growth velocity given the nutrition practices and factors associated with poor growth rates in north-eastern Tanzania.

Methods: This was a prospective cohort study conducted from December 2018 to May 2019. Participants born during this period were followed-up with their weight measurements taken weekly from day one to day 28 . Their weekly growth velocity was calculated using the two-point average weight model with the mean velocity for the first month extrapolated from the weekly velocities. $T$-test and ANOVA were used to compare the mean velocity, and logistic regression was used to analyze the association between the variables.

Results: We enrolled a total of 178 participants. The mean growth velocity was 12.7 $(\mathrm{SD}=1.2) \mathrm{g} / \mathrm{kg} /$ day. There was significant difference on the mean growth velocities of those with postnatal morbidity and those who had none. Delay in the initiation of the enteral feeds for more than $48 \mathrm{~h}$ was associated with 8.44 higher odds of slower growth rate $(95 \% \mathrm{CI}$ : 2.90-14.54). Babies born to mothers, who had maternal illness and those whom antenatal steroids for lung maturation were administered, were having significantly higher odds 6.94 (95\%CI: 2.07-13.28) and 2.61 [95\%CI: 1.04-6.59) of slower growth rate compared to their counterparts.

Conclusion: Given the nutritional practices in Northeastern Tanzania, our cohort showed suboptimal growth velocity compared to international standards. Early initiation of the enteral feeds could improve growth rates of the preterm babies in this low resource setting, depending on the tolerance, clinical status, and medical intervention performed in this population group.

Keywords: preterm, growth velocity, gestation age

\section{Introduction}

Preterm birth is a birth which has occurred before 37 weeks of gestation and it contributes up to $11 \%$ of all the births annually. ${ }^{1}$ The prevalence of preterm delivery is highest in the developing countries compared to developed ones $(12 \%$ vs $9 \%$ ) with low survival rate. ${ }^{2}$ In Northeastern Tanzania, the prevalence is $14.3 \%$, slightly higher than the average estimated for developing countries. ${ }^{1}$ 
The growth pattern of the preterm baby follows a similar trend as the infant born at term, however there is a greater weight loss in the preterm, which occurs approximately in the first two weeks postnatally, with the nadir reached around 4-7 days. In this period, a preterm infant can lose up to $15 \%$ of the birth weight before starting the journey to regain it. ${ }^{3}$ With adequate nutrition as well as medical and community care, the growth rate of a preterm, after postnatal weight loss stage, ought to be the same as the fetus of similar gestation age, which is $15 \mathrm{~g} /$ $\mathrm{kg}$ each day, to achieve the functional outcome comparable to the infants born at term. ${ }^{4}$

Despite the advancements in nutritional and medical care for preterm babies, inadequate postnatal growth still remains a global problem. This growth faltering among preterm babies in early infancy contributes to the large burden of undernutrition among children under five years of age, especially in Sub-Saharan Africa. ${ }^{5}$ The long-term effect of inadequate growth is further evidenced by the delayed catch-up growth of between eight and 20 years that they experience in later years. ${ }^{6}$

The failure to grow at the adequate rate can be of a medical, environmental, or nutritional background which could be maternal or neonatal in origin. ${ }^{3}$ We did this study to determine the velocity with which preterms grow, to describe the factors associated with the poor growth rate in the neonatal period (28 days), and to use the findings to recommend countermeasures to improve preterm growth and outcome.

\section{Methods}

We conducted a prospective, closed cohort, hospital-based study at Kilimanjaro Christian Medical Centre (KCMC), Northeastern Tanzania, from December 2018 to May 2019. KCMC is a zonal referral hospital, catering for around 15 million people serving between 500 and 800 inpatients with 630 official beds and 90 canvas, 40 baby incubators. It is also a research and teaching hospital. Its neonatal unit has an admission rate of 15-200 per month with preterm neonates accounting for $25 \%$ of admissions, with both medical and/or surgical conditions.

All preterm neonates admitted in the neonatal ward during the period of the study were enrolled and followedup for a period of 28 days after a written informed consent was sought from their parents. Patients with lifethreatening congenital malformations like gastroschisis which poses the highest mortality risk to the infant were excluded.

The following data were collected from the mothers of participants: demographic data, illness in pregnancy, HIV status, antenatal care attendance, steroids given before delivery. Information from the preterm neonates included: gestation age, birth weight, appropriateness of birth weight for gestation, presence of twins or triplets, initiation of the first feed, time at complete oral feed, mode of feeding, duration of hospital stay, respiratory distress syndrome (RDS) and hypothermia. Ethical approval was obtained from Kilimanjaro Christian Medical University College Research and Ethics Committee and we proceeded to conduct the study in accordance with the Declaration of Helsinki.

\section{Weight Measurement}

The weights of Inpatients in the unit were recorded on a weekly basis from the day of birth until discharge, with the digital weighing machine (SECA) calibrated Class III and with a graduation of $10 \mathrm{~g}$ for weight measurement and recorded. Following discharge, weights were continued to be measured once a week until day 28 on every postnatal follow-up clinic visit.

\section{Gestation Age Estimation}

Gestation age was extrapolated from the beginning of the mother's last menstrual period or by ultrasound taken during the first trimester. The age was correlated with the score from Ballard's chart.

\section{Growth Velocity Calculation}

Growth velocity (in $\mathrm{g} / \mathrm{kg} / \mathrm{day}$ ) was calculated for every neonate by two-point model for average weight, as shown in the following formula: ${ }^{7,8}$ Growthvelocity $=\frac{1000 \times(W n-W 1)}{(D n-D 1) \times \frac{(\underline{W n+W 1)})}{(1)}}$

Where, $\mathrm{W}=$ =weight in grams, $\mathrm{D}=$ day, $1=$ beginning of time interval in days, $\mathrm{n}=\mathrm{end}$ of time interval in days.

The calculated weekly growth velocities for the first four weeks were then arranged to give the mean growth velocity for each enrolled participant for the whole 28 days. ${ }^{9}$

\section{Data Analysis}

The data was entered into SPSS version 25 for cleaning and analysis. For descriptive statistics, mean and median with their respective measures of dispersion were used to 
describe continuous variables, frequencies, and proportions for categorical variables. Tables and figures were used for summarization of the variables. Student's $t$-test and analysis of variance (ANOVA) were used to compare the mean velocity among different subgroups. Logistic regression was used for association between the variables. A value of $P<0.05$ was considered statistically significant.

\section{Results}

During the study period, 268 preterm neonates were born at and/or admitted to the neonatal ward at KCMC. Of these, 178 participants were included in the final analysis (Figure 1). The majority of the participants were males 95 (53.4\%) with a mean birth weight of $1512.36 \mathrm{~g}(\mathrm{SD}=352.2)$. The mean gestation age at birth was $31.91(\mathrm{SD}=2.0)$ weeks and $(85.4 \%)$ were born as singleton (Table 1).

Overall, mothers of the participants had a mean age of 25 $(\mathrm{SD}=5.6)$ years with the majority having primary education or below (68.5\%). Most of them made fewer than four visits to the antenatal clinic before delivery (53.9\%) (Table 2).

The mean weight growth velocity in this study was found to be ( $\mathrm{SD}=1.2, \mathrm{~g} / \mathrm{kg} / \mathrm{day}, 95 \% \mathrm{CI}$ : $-0.53-20.89)$. On a weekly basis, the second week after birth, preterm babies had the slowest mean growth velocity of $6.8 \mathrm{~g} / \mathrm{kg} /$ day, compared to the third and fourth weeks, whereby during this period the growth velocity was 14.7 and $16.5 \mathrm{~g} / \mathrm{kg} /$ day, respectively (Figure 2).

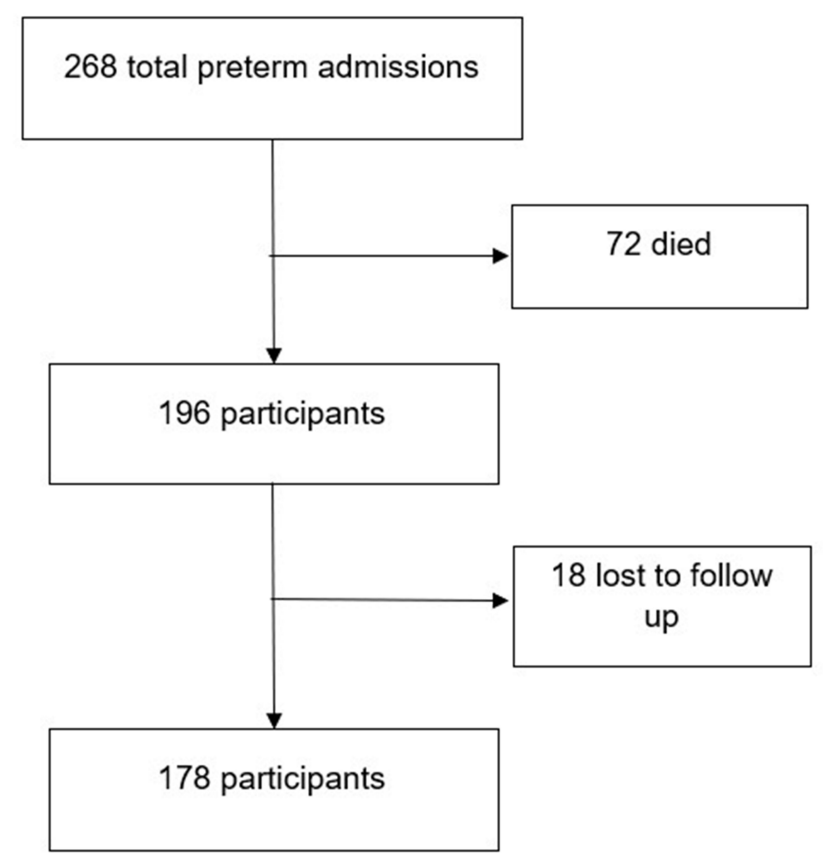

Figure I Number of patients enrolled and followed up to completion of the study $(\mathrm{N}=178)$.
Table I Characteristics of the Preterm Neonates $(\mathrm{N}=178)$

\begin{tabular}{|l|l|l|}
\hline Characteristic & N & $\%$ \\
\hline Sex & & \\
Male & 95 & 53.4 \\
Female & 83 & 46.6 \\
\hline Birth weight (grams) & & \\
$>1500$ & 84 & 47.2 \\
I000-I500 & 79 & 44.4 \\
$<1000$ & 15 & 8.4 \\
Mean (SD) & $1512.36(32.6)$ & \\
\hline Gestation age (weeks) & & \\
33-36 & 86 & 48.3 \\
$28-32$ & 92 & 51.7 \\
Mean (SD) & $31.91(2.0)$ & \\
\hline Size for GA & & 81.8 \\
AGA & 151 & 15.2 \\
SGA & 27 & \\
\hline Birth type & & \\
Single tone & 152 & \\
Multiple & 26 & \\
\hline First feed (hours) & 58.4 \\
$<48$ & $58.2(4.8)$ & \\
$\geq 48$ & & \\
Mean (SD) & & \\
\hline
\end{tabular}

Abbreviations: AGA, appropriate for gestation age; GA, gestation age; SGA, small for gestation age.

There was significant difference in growth velocity in rather than of the preterm babies who were initiated on their first oral feed in less than $48 \mathrm{~h}$ and those who were delayed. Those who started earlier grew at the significantly higher rate compared to those who were initiated later $(P<0.0001)$. Variation in the growth velocity was also seen in respect to other characteristics (sex, birth weight, gestation age, birth type, and size for gestation) but these were not statistically significant (Table 3 ).

In this study, it has been shown that preterm babies born to mothers with secondary education or higher and those who were born to mothers who were employed grew significantly at the higher velocity, $(P=0.007$ and $P=0.038)$ respectively, compared to their counterparts. Furthermore, preterm babies born to mothers with no illnesses during pregnancies, grew at a significantly faster velocity compared to those born to mothers who had various illnesses during pregnancy $(P=<0.0001)$. Babies born to mothers who had received steroids for fetal lung maturation grew at a slower rate compared to those whose mothers were not given steroids ( $P=0.003$ ) (Table 4). 
Table 2 Characteristics of the Mothers $(\mathrm{N}=178)$

\begin{tabular}{|c|c|c|}
\hline Characteristic & $\mathbf{N}$ & $\%$ \\
\hline \multicolumn{3}{|l|}{ Age } \\
\hline $15-19$ & 28 & 15.7 \\
\hline $20-29$ & 106 & 59.6 \\
\hline$\geq 30$ & 44 & 24.7 \\
\hline Mean (SD) & $25(2.9)$ & \\
\hline \multicolumn{3}{|l|}{ Marital status } \\
\hline Single & 54 & 30.3 \\
\hline Married & 86 & 48.3 \\
\hline Cohabiting & 38 & 21.4 \\
\hline \multicolumn{3}{|l|}{ Height $(\mathrm{cm})$} \\
\hline $150+$ & 51 & 28.7 \\
\hline$<150$ & 127 & 71.3 \\
\hline Mean (SD) & $146(4.3)$ & \\
\hline \multicolumn{3}{|l|}{ Level of education } \\
\hline Secondary/above & 56 & 31.5 \\
\hline Primary/below & 122 & 68.5 \\
\hline \multicolumn{3}{|l|}{ Occupation } \\
\hline Employed & 27 & 15.2 \\
\hline Unemployed & $15 \mid$ & 84.8 \\
\hline \multicolumn{3}{|l|}{ Number of antenatal visits } \\
\hline$\geq 4$ & 82 & 46.1 \\
\hline$<4$ & 96 & 53.9 \\
\hline Mean (SD) & $2.5(3.4)$ & \\
\hline \multicolumn{3}{|l|}{ HIV status } \\
\hline Negative & 174 & 97.8 \\
\hline Positive & 4 & 2.2 \\
\hline \multicolumn{3}{|l|}{ Illness in pregnancy } \\
\hline No & 142 & 79.8 \\
\hline Yes & 36 & 20.2 \\
\hline
\end{tabular}

Abbreviations: HIV, human immunodeficiency virus; SD, standard deviation.

There were significant differences in growth velocity among preterm babies with postnatal morbidities compared to those without. Those with RDS and sepsis grew at a significantly lower velocity compared to those without these conditions $(P=0.001$ and $P=0.005)$ respectively (Table 5).

In logistic regression analysis, babies who were initiated on their enteral feeds $>48 \mathrm{~h}$ had 8.44 (95\% CI: 2.90-14.54) higher odds of having velocity below the average compared to those initiated at later times. For birth weight below $1500 \mathrm{~g}$, antenatal steroids and maternal illnesses during pregnancy or labor were also seen to influence significantly lower velocities (Table 6).

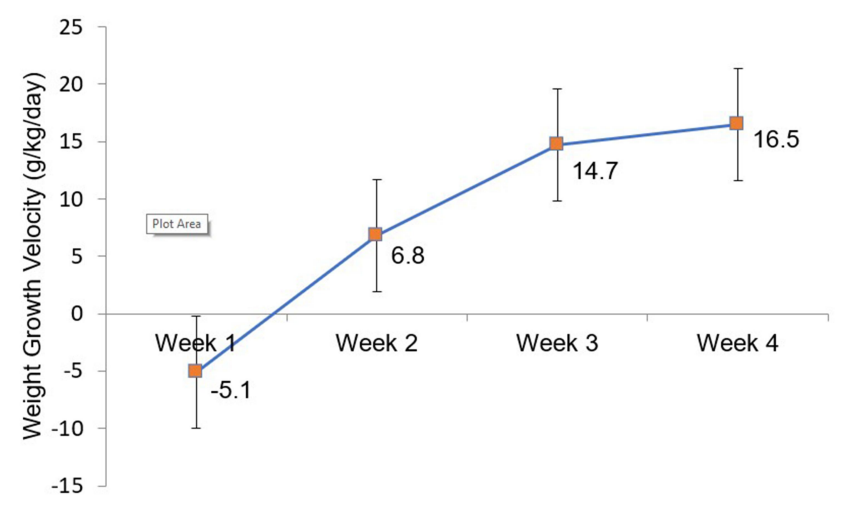

Figure 2 Weekly weight growth velocity for the four postnatal weeks of the preterm babies. Second week growth velocity was half of the intrauterine velocity of $15 \mathrm{~g} / \mathrm{kg} /$ day, an international standard recommended. ${ }^{4}$

\section{Discussion}

We found out that the mean weight growth velocity in preterm babies at $\mathrm{KCMC}$ is $12.7(\mathrm{SD}=1.2) \mathrm{g} / \mathrm{kg} /$ day during the first 28 days of life.

Table 3 Preterm Growth Velocity Variations Through Different Neonatal Characteristics $(\mathrm{N}=178)$

\begin{tabular}{|c|c|c|c|c|}
\hline \multirow{2}{*}{$\begin{array}{l}\text { Variables } \\
\text { Sex }\end{array}$} & $\begin{array}{l}\text { Mean (SD) (g/ } \\
\text { kg/day) }\end{array}$ & \multicolumn{2}{|l|}{$95 \% \mathrm{Cl}$} & \multirow[t]{2}{*}{$P$-value } \\
\hline & & & & \\
\hline Male & I3.2 (5.0) & $|2.202|$ & |4.2736 & $0.149^{\mathrm{a}}$ \\
\hline Female & $12.1(5.3)$ & 10.9625 & $|3.062|$ & \\
\hline \multicolumn{5}{|l|}{$\begin{array}{l}\text { Birth weight } \\
\text { (grams) }\end{array}$} \\
\hline$>1500$ & I $3.2(4.8)$ & 12.4897 & $|4.572|$ & $0.108^{b}$ \\
\hline $1000-1500$ & $12.8(3.4)$ & $10.958 \mid$ & | 4.7248 & \\
\hline$<1000$ & I I.8 (5.7) & 10.5339 & 13.1042 & \\
\hline \multicolumn{5}{|l|}{ Gestation age } \\
\hline (Weeks) & & & & \\
\hline$(33-34)$ & $13.9(5.3)$ & 11.8142 & 14.0697 & $0.57 \mathrm{I}^{\mathrm{a}}$ \\
\hline$(28-32)$ & $12.5(5.1)$ & 11.4356 & 13.5625 & \\
\hline \multicolumn{5}{|l|}{ Size for GA } \\
\hline SGA & $12.3(5.3)$ & 10.1733 & $|4.394|$ & $0.642^{\mathrm{a}}$ \\
\hline AGA & $12.8(5.2)$ & 11.9580 & 13.6216 & \\
\hline \multicolumn{5}{|l|}{$\begin{array}{l}\text { First feed } \\
\text { (Hrs) }\end{array}$} \\
\hline (Hrs.) & & & & \\
\hline$<48$ & | $4.3(4.8)$ & 13.3444 & 15.1697 & $<0.0001^{a}$ \\
\hline$\geq 48$ & $10.2(4.8)$ & 9.0582 & II. .3724 & \\
\hline \multicolumn{5}{|l|}{ Birth type } \\
\hline Single tone & $12.9(5.3)$ & II.0489 & I3.7545 & $0.242^{\mathrm{a}}$ \\
\hline Multiple & I I.6 (4.2) & 9.9026 & 13.3178 & \\
\hline
\end{tabular}

Notes: ${ }^{\mathrm{a}}$ T-test. ${ }^{\mathrm{b}} \mathrm{ANOVA}$ test

Abbreviations: AGA, appropriate for gestation age; GA, gestation age; SGA, small for gestation age. 
Table 4 Preterm Growth Velocity Variations Through Different Maternal Characteristics (N=178)

\begin{tabular}{|c|c|c|c|c|}
\hline Variables & Mean (SD) (g/Kg/Day) & \multicolumn{2}{|l|}{$95 \% \mathrm{Cl}$} & P-value \\
\hline \multicolumn{5}{|l|}{ Age } \\
\hline $15-19$ & |3.7(5.4) & II.5645 & 15.7879 & $0.564^{\mathrm{b}}$ \\
\hline $20-29$ & I 2.6(5.4) & 11.5189 & 13.5964 & \\
\hline $30+$ & $12.5(4.5)$ & II.1040 & 13.8448 & \\
\hline \multicolumn{5}{|l|}{ Height $(\mathrm{cm})$} \\
\hline $150+$ & $12 . \mid(5.2)$ & 10.5825 & 13.5276 & $0.285^{\mathrm{a}}$ \\
\hline$<150$ & I2.0(5.2) & II.0707 & 13.8839 & \\
\hline \multicolumn{5}{|l|}{ Level of education } \\
\hline Secondary/above & |4.2(5.0) & 12.9044 & 15.5740 & $0.007^{\mathrm{a}}$ \\
\hline Primary/below & $12.0(5.2)$ & 11.0903 & 12.9347 & \\
\hline \multicolumn{5}{|l|}{ Occupation } \\
\hline Employed & $14.6(5.1)$ & 12.6144 & 16.6170 & $0.038^{\mathrm{a}}$ \\
\hline Unemployed & I2.4(5.2) & I I.5446 & 13.2010 & \\
\hline \multicolumn{5}{|l|}{ HIV status } \\
\hline Positive & $12.7(5.2)$ & 11.9093 & 10.2730 & $0.711^{\mathrm{a}}$ \\
\hline Negative & $13.7(3.3)$ & II.5858 & 15.9446 & \\
\hline \multicolumn{5}{|l|}{ Illness in pregnancy } \\
\hline No & I3.7(4.9) & 12.8784 & 14.5073 & $<0.000 \mathrm{I}^{\mathrm{a}}$ \\
\hline Yes & $8.8(4.4)$ & 7.3485 & 10.3477 & \\
\hline \multicolumn{5}{|l|}{ Antenatal steroids } \\
\hline No & I3.6(5.2) & 12.6470 & $|4.623|$ & $0.003^{\mathrm{a}}$ \\
\hline Yes & II.3(4.89) & 10.1224 & 12.4586 & \\
\hline
\end{tabular}

Notes: ${ }^{a}$ t-test. ${ }^{b}$ ANOVA test

Abbreviation: HIV, human immunodeficiency virus.

Table 5 Preterm Growth Velocity Variations Through Different Postnatal Diseases $(\mathrm{N}=178)$

\begin{tabular}{|c|c|c|c|c|}
\hline Variables & Mean (SD) (g/kg/day) & \multicolumn{2}{|c|}{$(95 \% \mathrm{Cl})$} & $P$-value \\
\hline \multicolumn{5}{|l|}{ RDS } \\
\hline No & 12.3 & 10.3 & 13.5 & \\
\hline Yes & 7.6 & 4.86 & 10.0 & $0.00 \mathrm{I}^{\mathrm{a}}$ \\
\hline \multicolumn{5}{|l|}{ Sepsis } \\
\hline No & 12.5 & 11.2 & 13.7 & \\
\hline Yes & 8.9 & 6.4 & 11.4 & $0.005^{\mathrm{a}}$ \\
\hline \multicolumn{5}{|l|}{$\mathrm{CHD}$} \\
\hline No & 11.5 & 10.9 & 12.7 & \\
\hline Yes & 10.1 & 8.3 & 12.6 & $0.569^{\mathrm{a}}$ \\
\hline
\end{tabular}

Note: ${ }^{a}$-test.

Abbreviations: CHD, congenital heart diseases; RDS, respiratory distress syndrome.

There was variation in speed of growth in different weeks, the second week having the lowest rate of 6.8 $(\mathrm{SD}=13.9) \mathrm{g} / \mathrm{kg} /$ day compared to the third and the fourth week where most of the babies grew in a rate similar to the fetus's rate in the third trimester. The rate was $14.7(\mathrm{SD}=8.2)$ $\mathrm{g} / \mathrm{kg} /$ day and $16.5(\mathrm{SD}=7.5) \mathrm{g} / \mathrm{kg} /$ day, respectively.

There have been various velocities that have been documented in various countries. In Nigeria, for example, a lower growth velocity of $8.2 \pm 3.3 \mathrm{~g} / \mathrm{kg} /$ day was demonstrated. ${ }^{7}$ However, this lower velocity may be explained by the higher gestational ages of the participants enrolled in that study. Most participants in this survey (78.4\%) were term infants and, therefore, less likely to grow as fast as preterm infants who need to catch up.

In India, a higher mean growth rate of $15.18 \pm 1.7 \mathrm{~g} / \mathrm{kg} /$ day was reported. ${ }^{10}$ This is like the intrauterine growth velocity and what is recommended by WHO. Feeding practices were different compared to ours. In this cohort, infants were fed, once at $100 \mathrm{mls} / \mathrm{kg} /$ day intake, were fortified to increase the calories to $80 \mathrm{kcal} / 100 \mathrm{~mL}$ of human milk with an additional protein intake of $0.6 \mathrm{~g} / \mathrm{kg} /$ day.

Two studies in South Africa also reported higher growth rate compared with our study, one with the rate of $14 \mathrm{~g} / \mathrm{kg} /$ day in $2013^{9}$ and the other with $13.2(4.24) \mathrm{g} /$ 
Table 6 Logistic Regression Analysis for Predictors of Poor Growth Velocity Among Preterm Babies (N=178)

\begin{tabular}{|c|c|c|c|c|c|c|}
\hline Variables & COR & $(95 \% \mathrm{Cl})$ & $P$-value & AOR & $(95 \% \mathrm{Cl})$ & $P$-value \\
\hline \multicolumn{7}{|c|}{ Illness in pregnancy } \\
\hline No & 1 & & & 1 & & \\
\hline Yes & 4.27 & $1.82-10.00$ & 0.001 & 6.94 & $2.07-13.28$ & 0.001 \\
\hline \multicolumn{7}{|c|}{ Antenatal steroids } \\
\hline No & 1 & & & 1 & & \\
\hline Yes & 2.11 & $1.14-3.92$ & 0.034 & 2.61 & $1.04-6.59$ & 0.002 \\
\hline \multicolumn{7}{|c|}{ Sex of the baby } \\
\hline Male & 1 & & & 1 & & \\
\hline Female & 1.91 & $0.29-0.95$ & 0.034 & 2.34 & $1.09-5.02$ & 0.029 \\
\hline \multicolumn{7}{|c|}{ Birth weight (grams) } \\
\hline$>1500$ & I & & & 1 & & \\
\hline$\leq 1500$ & 1.24 & $0.69-2.24$ & 0.468 & 1.33 & $1.13-1.86$ & 0.021 \\
\hline \multicolumn{7}{|c|}{ Gestation age (weeks) } \\
\hline $33-36$ & 1 & & & I & & \\
\hline $28-32$ & 1.25 & $0.69-2.25$ & 0.462 & 1.08 & $0.45-2.60$ & 0.868 \\
\hline \multicolumn{7}{|l|}{ Size for GA } \\
\hline AGA & 1 & & & I & & \\
\hline SGA & 1.18 & $0.52-2.68$ & 0.690 & 0.58 & $0.21-1.61$ & 0.295 \\
\hline \multicolumn{7}{|c|}{ First feed (hours) } \\
\hline$<48$ & 1 & & & I & & \\
\hline$\geq 48$ & 3.60 & I.89-6.87 & $<0.001$ & 8.44 & $2.90-14.54$ & $<0.001$ \\
\hline \multicolumn{7}{|l|}{ Birth type } \\
\hline Singleton & 1 & & & I & & \\
\hline Multiple & 1.60 & $0.68-3.75$ & 0.279 & 1.72 & $0.50-5.93$ & 0.388 \\
\hline \multicolumn{7}{|l|}{ RDS } \\
\hline No & 1 & & & I & & \\
\hline Yes & 2.27 & $1.03-5.00$ & 0.042 & 2.32 & $(0.73-7.38)$ & 0.156 \\
\hline \multicolumn{7}{|l|}{ Sepsis } \\
\hline No & 1 & & & I & & \\
\hline Yes & 2.32 & I.19-4.53 & 0.014 & 1.93 & $(0.82-4.58)$ & 0.135 \\
\hline \multicolumn{7}{|l|}{$\mathrm{CHD}$} \\
\hline No & I & & & I & & \\
\hline Yes & 1.13 & $0.33-3.84$ & 0.845 & 0.52 & $(0.10-2.72)$ & 0.437 \\
\hline
\end{tabular}

Abbreviations: AGA, appropriate for gestation age; AOR, adjusted odds ratio; CHD, congenital heart diseases; COR, crude odds ratio; GA, gestation age; RDS, respiratory distress syndrome; SGA, small for gestation age.

$\mathrm{kg} / \mathrm{day}$ a year later. ${ }^{8}$ In both studies, infants were initiated with smaller oral feeds on the second day postnatally of around $10-20 \mathrm{mLs} / \mathrm{kg} /$ day incrementally. This was continued until full feeds after which point feeds were fortified with human milk fortifier.

Initiation of the first feed after $48 \mathrm{~h}$ of life has been a major factor leading to lower growth velocities among the preterm babies. Our study demonstrated a significant association between delaying initiation of the feeds and poor growth velocity among the preterm babies in our cohort upon regression analysis. This finding has been demonstrated in other studies-for example, in one Iranian cohort which showed that early initiation of the enteral feeds was associated with faster growing rates compared to those who were delayed. ${ }^{11}$ Furthermore, early regaining of birthweight was also noted in this group after the nadir weight loss was reached. It has been shown that early initiation of the feeds is associated 
with early maturation of the intestinal villi and hence tolerance of the enteral feeds. ${ }^{12,13}$ Early tolerance will allow more caloric intake as the feeds are advanced, hence promoting adequate growth. Definitely, early initiation of the enteral feeds, within $48 \mathrm{~h}$ of life could be the best method in the improvement of preterm growth rates, especially in a low resource setting, but we agree delay in initiating the feeds may be a function of, tolerance, clinical status, and medical intervention performed on individual neonates.

Moreover, babies born to mothers who were administered antenatal steroids for the lung maturation of their fetuses were showing a slower rate of growing and antenatal steroids showed significant association with a low growth velocity on logistic regression analysis. This correlated with the finding from two studies done in South Africa where antenatal steroids had an adverse effect on good growth velocity. ${ }^{8,9}$ One of the studies included only extreme low birth weight (ELBW) infants while the other included very low birth weight (VLBW) infants. Both had included similar gestation ages compared to the cohort used in our study.

Poor growth rate was seen in preterms born to mothers who had maternal illness prior to delivery. Maternal illnesses were adversely correlated to growth velocity of preterm babies when analyzed on a logistic regression model. This can be explained by the negative impact of illnesses such as malaria, gestation diabetes and hypertension on intrauterine growth of the fetus, the effect of which could also extend to the extrauterine growth.

In this study, postnatal morbidities did not significantly influence poor growth when adjusted on multilinear regression. This could be due to low sample size, however, there was lower mean velocity with significant difference between those who had sepsis and RDS compared to those who had none on a bivariate analysis.

\section{Strengths and Limitations}

Strength of this study is the long follow-up time of the babies to the age of 28 days. This provided a longer period to allow for full recovery of the postnatal weight loss of the preterm babies and therefore the true weight gain could be assessed with no bias.

The noninclusion of anthropometric measurements such as head circumference and length is the limitation of this study as it led to partial observation of the full growth package of study participants. In addition, this study was conducted in a single medical center and hence generalization of the study findings may be limited.

\section{Conclusion and Recommendation}

Preterm infants are growing at the mean velocity of $12.7 \mathrm{~g} /$ $\mathrm{kg} /$ day, which is slower than that recommended by the WHO (15 g/kg/day). Early initiation of the enteral feeds is associated to improved growth rates in this group. More research and randomized trials are needed to identify barriers, the best time to initiate, and how to advance the enteral feeds in this population without causing further morbidities and/or adverse outcomes.

\section{Abbreviations}

ELBW, extremely low birth weight; HIV, human immunodeficiency virus; KCMC, Kilimanjaro Christian Medical Center; VLBW, very low birth weight; WHO, World Health Organization.

\section{Acknowledgments}

We would like to thank the nurses in the Neonatal Unit at Kilimanjaro Christian Medical Centre for their support in data collection. We would also like to thank all colleagues, specialists, and consultants in the Department of Pediatrics and Child health at the hospital for their input on this study.

\section{Disclosure}

The authors report no conflicts of interest in this work.

\section{References}

1. Temu TB, Masenga G, Obure J, Mosha D, Mahande MJ. Maternal and obstetric risk factors associated with preterm delivery at a referral hospital in northern-eastern Tanzania. Asian Pac J Reprod. 2016;5 (5):365-370. doi:10.1016/j.apjr.2016.07.009

2. Rugaimukam JJ, Mahande MJ, Msuya SE, Rune N. Risk factors for preterm birth among women who delivered preterm babies at Bugando medical centre, Tanzania. SOJ Gynecol Obstet Women Health. 2017;3 (2):1-7. doi:10.15226/2381-2915/3/2/00124

3. Namiiro FB, Mugalu J, McAdams RM, Ndeezi G. Poor birth weight recovery among low birth weight/preterm infants following hospital discharge in Kampala, Uganda. BMC Pregnancy Childbirth. 2012;12 (1):1. doi:10.1186/1471-2393-12-1

4. De Curtis M, Rigo J. The nutrition of preterm infants. Early Hum Dev. 2012;88(Suppl 1):S5-7. doi:10.1016/j.earlhumdev.2011.12.020

5. Victora CG, de Onis M, Hallal PC, Blössner M, Shrimpton R. Worldwide timing of growth faltering: revisiting implications for interventions. Pediatrics. 2010;125(3):e473-80. doi:10.1542/ peds.2009-1519

6. Hack M, Schluchter M, Cartar L, Rahman M, Cuttler L, Borawski E. Growth of very low birth weight infants to age 20 years. Pediatrics. 2003;112(1):e30-8. doi:10.1542/peds.112.1.e30

7. Olusanya BO, Renner JK. Predictors of growth velocity in early infancy in a resource-poor setting. Early Hum Dev. 2011;87 (10):647-652. doi:10.1016/j.earlhumdev.2011.05.002

8. Mudahemuka JC, Ballot DE. Birth weight recovery among very low birth weight infants surviving to discharge from Charlotte Maxeke Johannesburg academic hospital, neonatal unit. S Afr j Child Health. 2014;8(4):149. doi:10.7196/sajch.709 
9. Lango MO, Horn AR, Harrison MC. Growth velocity of extremely low birth weight preterms at a tertiary neonatal unit in South Africa. $J$ Trop Pediatr. 2013;59(2):79-83. doi:10.1093/tropej/fms049

10. Saluja S, Modi M, Kaur A, et al. Growth of very low birth-weight Indian infants during hospital stay. Indian Pediatr. 2010;47 (10):851-856. doi:10.1007/s13312-010-0146-7

11. Sallakh-Niknezhad A, Bashar-Hashemi F, Satarzadeh N, Ghojazadeh M, Sahnazarli G. Early versus late trophic feeding in very low birth weight preterm infants. Iran J Pediatr. 2012;22 (2):171-176.
12. Berseth CL. Effect of early feeding on maturation of the preterm infant's small intestine. J Pediatr. 1992;120(6):947-953. doi:10.1016/ S0022-3476(05)81969-9

13. Berseth CL, Nordyke C. Enteral nutrients promote postnatal maturation of intestinal motor activity in preterm infants. Am J Physiol. 1993;264(6 Pt 1):G1046-51. doi:10.1152/ajpgi.1993.264.6.G1046

\section{Publish your work in this journal}

Research and Reports in Neonatology is an international, peerreviewed, open access journal publishing original research, reports, editorials, reviews and commentaries on neonatal health. The manuscript management system is completely online and includes a very quick and fair peer-review system. Visit http://www.dovepress. com/testimonials.php to read real quotes from published authors. 